\title{
ESURFD
}

$2,1-17,2014$

\section{Short Communication: Earth is (mostly) flat, but mountains dominate global denudation: apportionment of the continental mass flux over millennial time scales, revisited}

J. K. Willenbring ${ }^{1}$, A. T. Codilean ${ }^{2}$, K. L. Ferrier ${ }^{3}$, B. McElroy ${ }^{4}$, and J. W. Kirchner ${ }^{5}$

${ }^{1}$ Department of Earth and Environmental Science, University of Pennsylvania, 240 S. 33rd St., Hayden Hall, Philadelphia, Pennsylvania 19104, USA

${ }^{2}$ School of Earth \& Environmental Science, University of Wollongong, Wollongong 2500, New South Wales, Australia

${ }^{3}$ Department of Earth and Planetary Sciences, Harvard University, Cambridge, MA, 02138, USA

${ }^{4}$ Department of Geology and Geophysics, University of Wyoming, Laramie, Wyoming 82071 , USA

${ }^{5}$ Swiss Federal Research Institute WSL, Birmensdorf, and Department of Environmental Sciences, ETH Zurich, 8092 Zurich, Switzerland

\section{Earth is (mostly) flat, but mountains dominate global denudation \\ J. K. Willenbring et al.}

Title Page

Abstract Introduction

Conclusions

References

Tables

14

$<$

Back
- I

Close

Full Screen / Esc

Printer-friendly Version

Interactive Discussion 
Received: 8 January 2014 - Accepted: 10 January 2014 - Published: 29 January 2014

Correspondence to: J. K. Willenbring (erosion@sas.upenn.edu)

Published by Copernicus Publications on behalf of the European Geosciences Union.

\section{ESURFD}

2, 1-17, 2014

Earth is (mostly) flat, but mountains dominate global denudation

J. K. Willenbring et al.

Title Page

Abstract

Introduction

Conclusions

References

Tables

Figures

14

I

4

Back

Close

Full Screen / Esc

Printer-friendly Version

Interactive Discussion 


\section{Abstract}

Carbon dioxide consumption by silicate mineral weathering and the subsequent precipitation of carbonate sediments sequesters $\mathrm{CO}_{2}$ over geologic timescales. The rate of this carbon sequestration is coupled to rates of continental erosion, which exposes 5 fresh minerals to weathering. Steep mountain landscapes represent a small fraction of continental surfaces but contribute disproportionately to global erosion rates. However, the relative contributions of Earth's much vaster, but more slowly eroding, plains and hills remain the subject of debate. Recently, Willenbring et al. (2013) analyzed a compilation of denudation rates and topographic gradients and concluded that lowgradient regions dominate global denudation fluxes and silicate weathering rates. Here, we show that Willenbring et al. (2003) topographic and statistical analyses were subject to methodological errors that affected their conclusions. We correct these errors, and reanalyze their denudation rate and topographic data. In contrast to the results of Willenbring et al. (2013), we find that the denudation flux from the steepest $10 \%$ of continental topography nearly equals the flux from the other $90 \%$ of the continental surface combined. This new analysis implies global denudation fluxes of $\sim 23 \mathrm{Gt} \mathrm{yr}^{-1}$, roughly five times the value reported in Willenbring et al. (2013) and closer to previous estimates found elsewhere in the literature. Although low-gradient landscapes make up a small proportion of the global fluxes, they remain important because of the human reliance, and impact, on these vast areas.

\section{Introduction}

Over timescales longer than $\sim 100000 \mathrm{yr}, \mathrm{CO}_{2}$ levels in the atmosphere, hydrosphere, and biosphere are regulated by the balance between $\mathrm{CO}_{2}$ production by volcanism and metamorphic decarbonation reactions in collisional orogens, and $\mathrm{CO}_{2}$ consumption by chemical weathering of silicate minerals and the subsequent precipitation of carbonate sediments (e.g., Chamberlin, 1898; Walker et al., 1981; Berner et al., 1983).

\section{ESURFD}

2, 1-17, 2014

\section{Earth is (mostly) flat, but mountains dominate global denudation}

\section{J. K. Willenbring et al.}

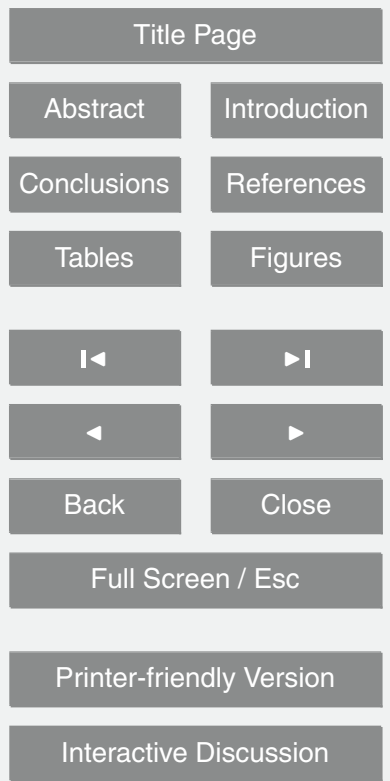


The long-term stability of atmospheric $\mathrm{CO}_{2}$ (and thus global climate) is determined by the strength of the negative feedback between atmospheric $\mathrm{CO}_{2}$ and mineral weathering rates (Berner and Caldeira, 1997). To the extent that $\mathrm{CO}_{2}$ sequestration by mineral weathering depends on the supply of weatherable minerals that become exposed 5 through erosion (Riebe et al., 2001; West et al., 2005), erosional processes play a key role in the negative feedback between atmospheric $\mathrm{CO}_{2}$ and mineral weathering rates, and tectonically or climatically driven variations in erosion rates can potentially lead to global cooling (e.g., Molnar and England, 1990; Raymo and Ruddiman, 1992).

The potentially pivotal role of physical erosion and chemical weathering in the global 10 climate system has spurred intense interest in estimating global rates of erosion and weathering, and determining what controls them. A recurring theme in weathering studies is the importance of rapid erosion in steep mountain regions. All else equal, erosion rates increase nonlinearly with hillslope gradients (e.g., Montgomery and Brandon, 2002), particularly in landscapes subject to active tectonics or base-

level lowering (Riebe et al., 2000). Thus, steep mountain landscapes contribute to global erosion rates disproportionately to their relatively small fraction of Earth's surface (Fig. 1). Mountain landscapes may also contribute disproportionately to global weathering fluxes, particularly where weathering rates are limited by mineral supply rather than mineral dissolution kinetics (Riebe et al., 2001; West et al., 2005). However, rapid erosion of steep terrain also creates thin soils with short mineral residence times, limiting the amount of weathering that may occur on mountain slopes themselves (Anderson et al., 2002; Ferrier and Kirchner, 2008; Dixon et al., 2012). The sediment supplied by rapidly eroding hillslopes to streams may therefore be relatively susceptible to further weathering. If this minimally weathered sediment is deposited on

floodplains and weathers there, then the most important contribution of rapidly eroding mountains to chemical weathering may not be in the mountains themselves, but rather in the surrounding lowland floodplains (e.g., Lupker et al., 2012).

Recently, Willenbring et al. (2013) proposed that, although steep mountain regions have denudation rates (physical erosion and chemical weathering rates, summed to-

\section{ESURFD}

2, 1-17, 2014

\section{Earth is (mostly) flat, but mountains dominate global denudation}

J. K. Willenbring et al.

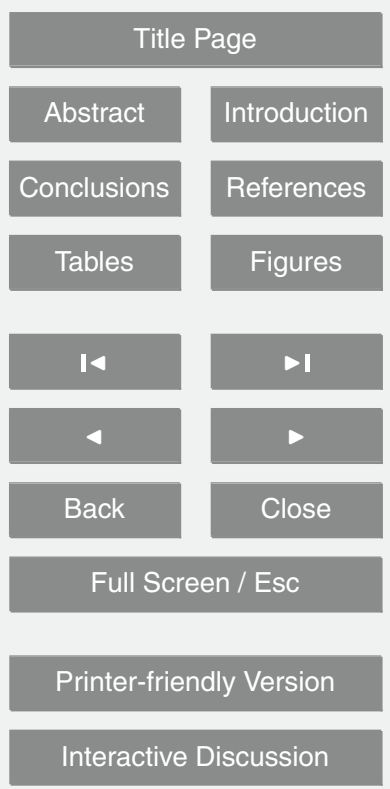


gether) that greatly exceed those in gentler terrain on a per-area basis, steep landscapes are such a small fraction of the globe (Fig. 1) that they do not dominate global production of either solutes or sediments. Here, we revisit Willenbring et al. (2013) analysis and several of their more provocative conclusions. Our reanalysis reveals several 5 methodological issues in Willenbring et al. (2013) analysis, and shows that correcting these issues substantially alters their conclusions.

\section{Reanalysis of Willenbring et al. (2013)}

Willenbring et al. (2013) calibrated an exponential rate equation to a compilation of cosmogenic ${ }^{10} \mathrm{Be}$ measurements of whole-catchment denudation rates from 990 drainage basins around the world. For each of these drainage basins, they estimated mean topographic slope from the 3-arc-second (approximately $90 \mathrm{~m}$ ) SRTM digital elevation model (DEM). They used ordinary least squares regression to fit the cosmogenic denudation rates $D\left(\mathrm{~mm} \mathrm{kyr}^{-1}\right)$ to an exponential function of the SRTM topographic slopes in $\mathrm{m} \mathrm{km}^{-1}(D=11.9 \exp (0.0065$. slope $))$. They then extrapolated this relationship to the 15 globe using the 30 -arc-second (approximately $1 \mathrm{~km}$ ) GTOPO30 DEM. Applying the exponential rate equation to slopes at individual points, although it was derived from average slopes for whole basins, would have created an upward bias in the denudation rate estimates. Therefore Willenbring et al. (2013) first averaged the GTOPO30 slopes in $25 \mathrm{~km}^{2}$ windows to mimic the averaging of slopes from the calibration basins 20 (which had a median drainage area of $27 \mathrm{~km}^{2}$ ). Willenbring et al. (2013) then applied the exponential $D$ vs. slope relationship to the smoothed global slope grid, and used the resulting map of denudation rates to estimate global mass fluxes to the oceans.

Three surprising conclusions resulted from Willenbring et al. (2013) analysis. First, denudation rates were found to be uncorrelated with hillslope gradients below slopes 25 of $200 \mathrm{~m} \mathrm{~km}^{-1}$. Second, the total continental denudation flux was found to be only $5.5 \mathrm{Gtyr}^{-1}$ (of which $4.4 \mathrm{Gtyr}^{-1}$ was calculated to reach the oceans, with the rest being trapped in endorheic basins), whereas most previous estimates have ranged between

\section{ESURFD}

2, 1-17, 2014

\section{Earth is (mostly) flat, but mountains dominate global denudation}

J. K. Willenbring et al.

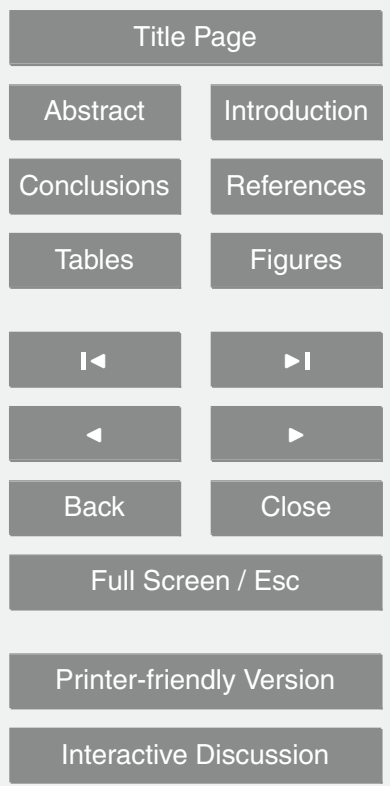


roughly 8 and $25 \mathrm{Gtyr}^{-1}$ (Willenbring et al. (2013), Table DR2). Third, steep mountainous terrain was found to make a surprisingly small contribution to the global denudation flux. Landscapes with average slopes of less than $20 \mathrm{~m} \mathrm{~km}^{-1}$ were found to account for $67 \%$ of the continental land surface and $54 \%$ of the denudation flux, whereas land5 scapes with slopes greater than $200 \mathrm{~m} \mathrm{~km}^{-1}$ were found to account for only $1 \%$ of the land surface and only $6 \%$ of the denudation flux.

\subsection{Mismatch in topographic resolution}

Because the $90 \mathrm{~m}$ SRTM DEM that Willenbring et al's. (2013) used to calibrate their denudation rate equation does not cover the entire globe, they used the coarserresolution $1 \mathrm{~km}$ GTOPO30 DEM to calculate global denudation rates. This mismatch in topographic resolution makes their results vulnerable to the well-known dependence of DEM slopes on DEM grid scale (e.g., Zhang and Montgomery, 1994). This slope bias arises because elevation measurements that are more widely spaced are more likely to straddle valleys and ridges, and thus are more likely to underestimate the average 15 slope of the surface (Kirchner and Ferrier, 2013). This bias increases with increasing slope, but also depends on the variability of the topographic surface over different length scales (e.g., Zhang et al., 1999), making it difficult to estimate a priori. We can obtain a first estimate of the slope bias by comparing the average slopes obtained from $90 \mathrm{~m}$ and $1 \mathrm{~km}$ DEMs for Willenbring et al's. (2013) 990 calibration drainage basins. On average, the slopes obtained from the $1 \mathrm{~km}$ DEMs are only $0.381 \pm 0.006$ (mean \pm standard error) times the slopes obtained from the $90 \mathrm{~m}$ DEMs for the same drainage basins. This has two immediate implications. The first implication is that Willenbring et al.'s (2013) analysis has systematically underestimated global topographic slopes, and thus global denudation rates (Kirchner and Ferrier, 2013). The second implication is that Willenbring et al.'s (2013) analysis has systematically underestimated the importance of steep terrain relative to gentler terrain, because $1 \mathrm{~km}$ slopes are much less variable from place to place than $90 \mathrm{~m}$ slopes are.

\section{ESURFD}

2, 1-17, 2014

\section{Earth is (mostly) flat, but mountains dominate global denudation}

J. K. Willenbring et al.

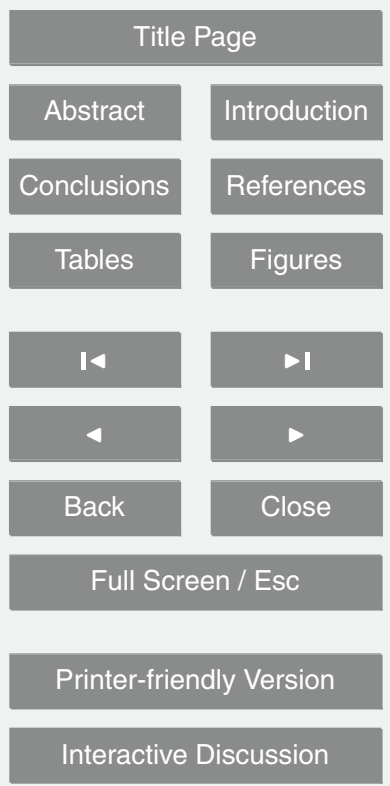


The topographic resolution bias in Willenbring et al.'s (2013) analysis can be eliminated if the denudation rate equation is calibrated at the same topographic resolution as the global database that it is extrapolated to; topographic slopes will still be underestimated (by an amount that depends on the grid scale), but they will be underestimated 5 consistently between the calibration and extrapolation data sets. The $90 \mathrm{~m}$ SRTM data set cannot be used because its coverage is not global, and although the $1 \mathrm{~km}$ GTOPO30 DEM has global coverage and could be used, it may yield unreliable slope estimates for many calibration basins that have drainage areas of only a few square kilometers. Therefore, our approach here is to use the global $250 \mathrm{~m}$ GMTED2010 to10 pographic data set, both to calibrate a new denudation rate equation (Fig. 2) and to extrapolate this equation to the globe (Fig. 1).

\subsection{Logarithmic transformation bias}

A plot of denudation rate vs. mean $(250 \mathrm{~m})$ topographic slope for Willenbring et al.'s (2013) calibration basins shows a clear exponential trend (Fig. 2). For a given 15 topographic slope, however, denudation rates of individual basins typically vary over $2-3$ orders of magnitude. An equation that is fitted to these individual log-transformed data points (as Willenbring et al. 2013) will be biased, because it will approximate the mean of the logarithm of the denudation rate, which is systematically lower than the logarithm of the mean of the denudation rate.

20 A simple statistical method for estimating this log-transformation bias is available (Ferguson, 1986), and when applied to Willenbring et al.'s (2013) original data it suggests that their calibrated equation has underestimated denudation rates by an average of roughly 0.8 natural log units, or roughly a factor of two. We can almost completely eliminate the log transformation bias - and simultaneously visualize the central points in Fig. 2, we fit it to the log of the average denudation rates for a series of bins (the yellow circles in Fig. 2). In Fig. 2 these bins each contain equal numbers of points, in rank order of increasing slope. Equalizing the number of points yields

\section{ESURFD}

2, 1-17, 2014

\section{Earth is (mostly) flat, but mountains dominate global denudation}

J. K. Willenbring et al.

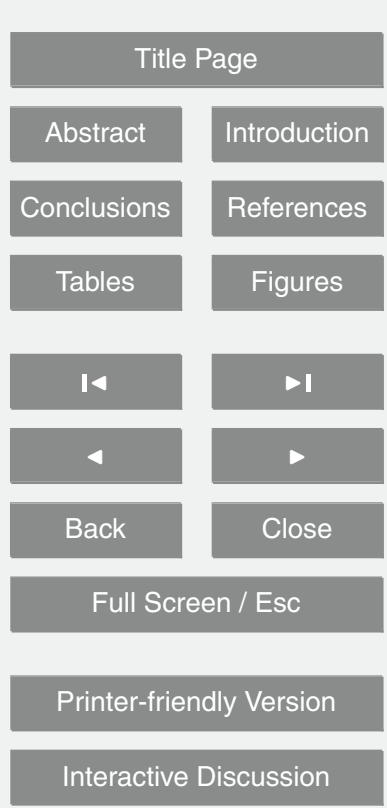

Interactive Discussion 
roughly comparable uncertainties in each of the binned averages, and therefore is preferable to taking averages over equal ranges of slope (which would have widely varying numbers of points and thus widely differing uncertainties in the averages, making the regression less robust). To obtain a maximum-likelihood estimate for the cal5 ibration equation, we weight the log-linear regression by the inverse of the squared (logarithmic) uncertainty in the binned means. The resulting denudation rate equation is $D=28.07^{\star} \exp \left(0.00744^{\star}\right.$ slope $)$, where slope is measured at $250 \mathrm{~m}$ DEM resolution.

\subsection{Spatial averaging of topographic gradients}

The variability of basin-averaged slopes in our calibration data set is obviously much 10 smaller than the variability of slopes at individual points in those basins. Therefore, extrapolating our calibration equation to the global GMTED DEM requires a smoothing routine that mimics the averaging of slopes in our calibration basins. Willenbring et al. (2013) computed a smoothed global slope grid by applying a circular moving window with an area equal to the median area of all sampled basins; we refer to this as 15 "median" smoothing.

Here, we compute a new smoothed global slope grid as the weighted average of 31 slope grids, each calculated by applying a circular moving window with an area between 2 and 225 pixels to the raw GMTED DEM. We weight each of the 31 slope grids according to the proportion of basins in the cosmogenic nuclide compilation that have the same drainage area as the smoothing window used to generate that grid. Compared to the "median" smoothing that Willenbring et al. (2013) used, this "multiscale" smoothing better mimics the smoothing that is inherent in the calibration data set. We compare the median and multiscale smoothing methods to test their impact on the modeled denudation fluxes.

\section{ESURFD}

2, 1-17, 2014

\section{Earth is (mostly) flat, but mountains dominate global denudation}

J. K. Willenbring et al.

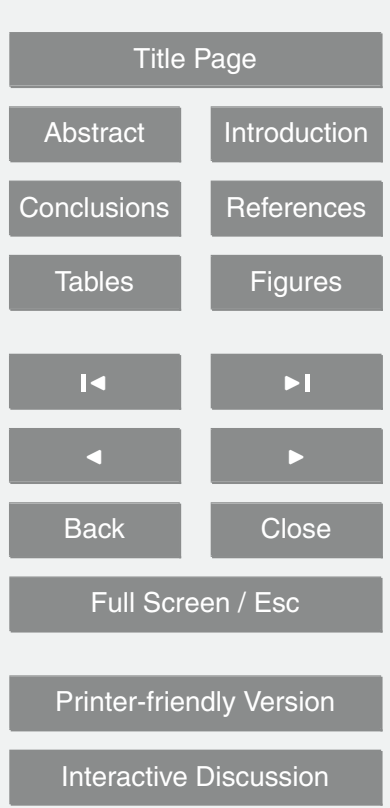




\section{Results}

The methodological improvements outlined above substantially alter the three surprising results reported by Willenbring et al. (2013). First, whereas Willenbring et al. (2013) concluded that denudation rates were essentially constant for slopes

5 less than $200 \mathrm{~m} \mathrm{~km}^{-1}$, Fig. 2 shows that denudation rates exhibit an exponential dependence on average hillslope gradients across the entire range of sampled gradients, even those $<200 \mathrm{~m} \mathrm{~km}^{-1}$. In Willenbring et al.'s (2013) Fig. 2A and B, the visual impression of slope-independent denudation rates arises from individual basins with near-zero denudation rates and thus very low logarithmic values at slopes near $10200 \mathrm{~m} \mathrm{~km}^{-1}$. Second, our updated calculations result in estimated global denudation fluxes of $\sim 23 \mathrm{Gtyr}^{-1}$, which is broadly consistent with previous estimates (Milliman and Syvitski, 1992; see also Table DR1 in Willenbring et al., 2013), but is roughly five times the value reported by Willenbring et al. (2013).

Finally, in our updated calculations, steep terrain accounts for a much larger propor15 tion of the global denudation flux (Fig. 3). Our updated calculations indicate that the steepest $50 \%, 20 \%$, and $10 \%$ of the continental land mass account for $77 \%, 59 \%$, and $48 \%$ of the denudation flux, respectively, whereas in Willenbring et al.'s (2013) original results the corresponding proportions were $60 \%, 33 \%$, and $22 \%$, respectively (Fig. 4). The different smoothing algorithms have a negligible effect on these fluxes 20 (Fig. 4).

\section{Discussion}

The currently available compilations of cosmogenically-inferred denudation rates (Portenga and Bierman, 2011; Willenbring et al., 2013) arguably represent the best available current data on long-term denudation rates, but they are far from comprehensive. Methodological constraints restrict cosmogenic ${ }^{10} \mathrm{Be}$ denudation rate measurements to quartz-bearing lithologies, which may be less susceptible to mass losses via

\section{ESURFD}

2, 1-17, 2014

\section{Earth is (mostly) flat, but mountains dominate global denudation}

J. K. Willenbring et al.

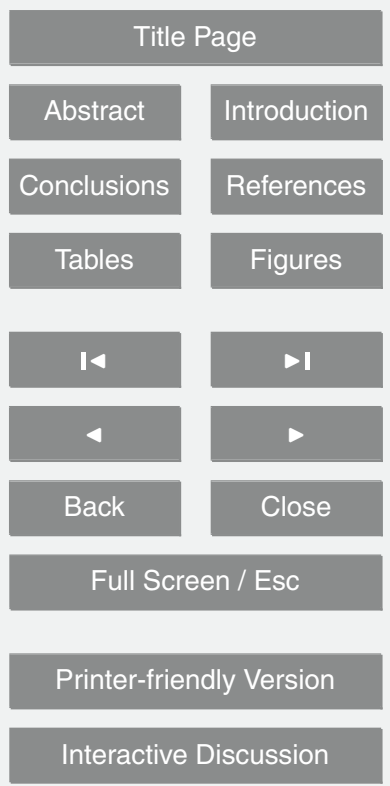


chemical weathering than more mafic lithologies, and also to locations where denudation rates are not so fast that ${ }^{10} \mathrm{Be}$ concentrations become unmeasurably low. Although each of the available cosmogenic compilations contains roughly 1000 measurements, their geographical distribution is neither uniform nor random; instead, they are strongly 5 clustered into a relatively small number of field study localities, representing the particular interests of individual investigators.

In particular, low-gradient landscapes are dramatically under-represented in these global compilations. In Willenbring et al.'s (2013) source data, for example, only $1 \%$ of the available ${ }^{10} \mathrm{Be}$ measurements come from drainage basins with average slopes 10 shallower than $22 \mathrm{~m} \mathrm{~km}^{-1}$ (at $250 \mathrm{~m} \mathrm{DEM}$ resolution), despite the fact that such landscapes comprise fully half of the continental land surface of the Earth. The source data also present a biased view of low-gradient terrain, because cosmogenic nuclides can measure mass loss rates but not mass accumulation rates, whereas many low-gradient areas are flat precisely because they are depositional. Applying the calibrated relationship between denudation rate and slope to depositional regions will necessarily lead to overpredictions of the mass fluxes from these regions (Kirchner and Ferrier, 2013).

The relative lack of scientific attention to erosional processes in low-gradient terrain is problematic. Although low-gradient landscapes do not dominate the global weathering budget, they do comprise most of the continental land mass, and they are where most of us live. Moreover, they are where human activities have the greatest impact on erosion and weathering, partly because we are so active there, partly because these areas are so extensive, and partly because the "background" rates are probably relatively lower in flatter terrain. These low-gradient regions are also particularly important because they are where most of our agriculture is done, and hence where soil erosion has the biggest consequences for the long-term sustainability of food production (Montgomery, 2007). Thus there is a clear need for better understanding of erosional processes in low-gradient landscapes.

\section{ESURFD}

2, 1-17, 2014

\section{Earth is (mostly) flat, but mountains dominate global denudation}

J. K. Willenbring et al.

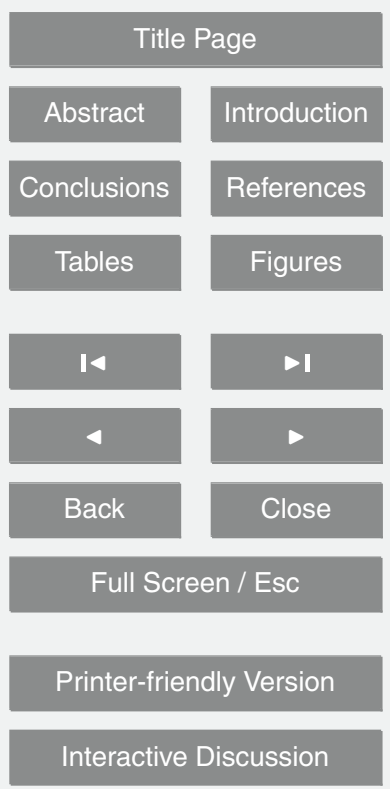




\section{Conclusions}

Our reassessment of the relationship between topographic gradient and denudation rate has generated several results that differ from those in Willenbring et al. (2013). Most importantly, this new analysis suggests that (1) in regions with gradients < $5200 \mathrm{~m} \mathrm{~km}^{-1}$, denudation rates increase exponentially with gradient, rather than stay constant; (2) global denudation fluxes total $\sim 23 \mathrm{Gtyr}^{-1}$, not $4.4 \mathrm{Gtyr}^{-1}$; and (3) most of the continental denudation flux comes from steep terrain, not low gradient terrain. This new analysis suggests, for instance, that nearly $50 \%$ of the world's total denudation flux comes from the steepest $10 \%$ of the continental terrain.

Although denudation fluxes in low-gradient landscapes are not the single dominant fraction of the global total, they are nonetheless important as objects of study. Lowgradient regions cover most of the planet's continental surface area, and they are where most people live and where the Earth's surface is most intensively sculpted by human activity. Because low-gradient landscapes tend to have low background sediment fluxes, they are also where humans have the most leverage to amplify sediment fluxes above background rates. However, scientific progress in this area is hampered by the scarcity of long-term denudation rate measurements in low-gradient regions. As a result, our current understanding of the controls on mass fluxes in these regions is poor. This makes it difficult to quantify how much low-gradient regions have contributed to global sediment fluxes in the past, and how people are likely to affect sediment fluxes and silicate weathering rates in the future. We suggest that low-gradient regions are particularly fertile ground for denudation and weathering studies.

Acknowledgements. We thank a number of people who contributed constructively to the corrections presented here including K. Norton, J.-D. Champanac, and B. Wilkinson.

\section{ESURFD}

2, 1-17, 2014

\section{Earth is (mostly) flat, but mountains dominate global denudation}

\section{J. K. Willenbring et al.}

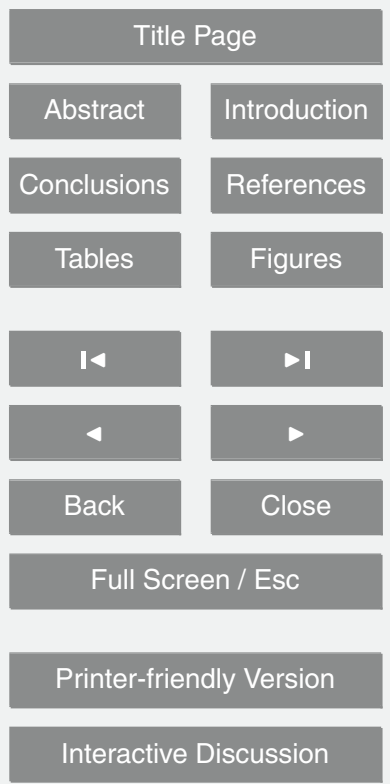




\section{References}

Anderson, S. P., Dietrich, W. E., and Brimhall, G. H.: Weathering profiles, mass-balance analysis, and rates of solute loss: linkages between weathering and erosion in a small, steep catchment, Geol. Soc. Am. Bull., 114, 1143-1158, 2002.

5 Berner, R. A., Lasaga, A. C., and Garrels, R. M.: The carbonate-silicate geochemical cycle and its effect on atmospheric carbon dioxide over the past 100 million years, Am. J. Sci., 283, 641-683, 1983.

Berner, R. A. and Caldeira, K.: The need for mass balance and feedback in the geochemical carbon cycle, Geology, 25, 955-956, 1997.

Chamberlin, T. C.: The influence of great epochs of limestone formation upon the constitution of the atmosphere, J. Geol., 6, 609-621, 1898.

Dixon, J. L., Hartshorn, A. S., Heimsath, A. M., DiBiase, R. A., and Whipple, K. X.: Chemical weathering response to tectonic forcing, A soils perspective from the San Gabriel Mountains, California, Earth Planet. Sc. Lett., 323-324, 40-49, 2012.

15 Ferguson, R. I.: River loads underestimated by rating curves, Water Res. Res., 22, 74-76, 1986.

Ferrier, K. L. and Kirchner, J. W.: Effects of physical erosion on chemical weathering rates, a numerical modeling study of soil-mantled landscapes, Earth Planet. Sc. Lett., 272, 591599, 2008.

20 Granger, D. E., Kirchner, J. W., and Finkel, R. C.: Spatially averaged long-term erosion rates measured from in situ cosmogenic nuclides in alluvial sediment, J. Geol., 104, 249-257, 1996.

Kirchner, J. W. and Ferrier, K. L.: Earth science: mainly in the plain, Nature, 495, 318-319, 2013.

Lupker, M., France-Lanord, C., Galy, V., Lave, J., Gaillardet, J., Gajurel, A. P., Guilmette, C., Rahman, M., Singh, S. K., and Sinha, R.: Predominant floodplain over mountain weathering of Himalayan sediments (Ganga basin), Geochim. Cosmo. Acta, 84, 410-432, 2012.

Milliman, J. D. and Syvitski, J. P.: Geomorphic/tectonic control of sediment discharge to the ocean, the importance of small mountainous rivers, J. Geol., 100, 525-544, 1992.

30 Molnar, P. and England, P.: Late Cenozoic uplift of mountain ranges and global climate change: chicken or egg?, Nature, 346, 29-34, 1990.

\section{ESURFD}

2, 1-17, 2014

\section{Earth is (mostly) flat, but mountains dominate global denudation}

J. K. Willenbring et al.

Title Page

Abstract

Introduction

Conclusions

Tables

References

Figures

I4

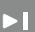

4

Back

Close 
Montgomery, D. R.: Soil erosion and agricultural sustainability, Proc. Nat. Acad. Sci. USA, 104, 13268-13272, 2007.

Montgomery, D. R. and Brandon, M. T.: Topographic controls on erosion rates in tectonically active mountain ranges, Earth Planet. Sc. Lett., 201, 481-489, 2002.

\section{ESURFD}

2, 1-17, 2014

5 Portenga, E. W. and Bierman, P. R.: Understanding Earth's eroding surface with ${ }^{10} \mathrm{Be}$, GSA Today, 21, 4-10, 2011.

Raymo, M. E. and Ruddiman, W. F.: Tectonic forcing of late Cenozoic climate, Nature 359, 117-122, 1992.

Riebe, C. S., Kirchner, J. W., Granger, D. E., and Finkel, R. C.: Erosional equilibrium and disequilibrium in the Sierra Nevada, inferred from cosmogenic ${ }^{26} \mathrm{Al}$ and ${ }^{10} \mathrm{Be}$ in alluvial sediment, Geology, 28, 803-806, 2000.

Riebe, C. S., Kirchner, J. W., Granger, D. E., and Finkel, R. C.: Strong tectonic and weak climatic control of long-term chemical weathering rates, Geology, 29, 511-514, 2001.

Walker, J. C. G., Hays, P. B., and Kasting, J. F.: A negative feedback mechanism for the longterm stabilization of Earth's surface-temperature, J. Geophys. Res., 86, 9776-9782, 1981.

West, A. J., Galy, A., and Bickle, M.: Tectonic and climatic controls on silicate weathering, Earth Planet. Sc. Lett., 235, 211-228, 2005.

Willenbring, J. K., Codilean, A. T., and McElroy, B.: Earth is (mostly) flat: apportionment of the flux of continental sediment over millennial time scales, Geology, 41, 343-346, 2013.

20 Zhang, W. and Montgomery, D. R.: Digital elevation model grid size, landscape representation, and hydrologic simulations, Water Resour. Res., 30, 1019-1028, 1994.

Zhang, X., Drake, N. A., Wainwright, J., and Mulligan, M.: Comparison of slope estimates from low resolution DEMs, Scaling issues and a fractal method for their solution, Earth Surf. Proc. Land., 24, 763-779, 1999.

\section{Earth is (mostly) flat, but mountains dominate global denudation}

J. K. Willenbring et al.

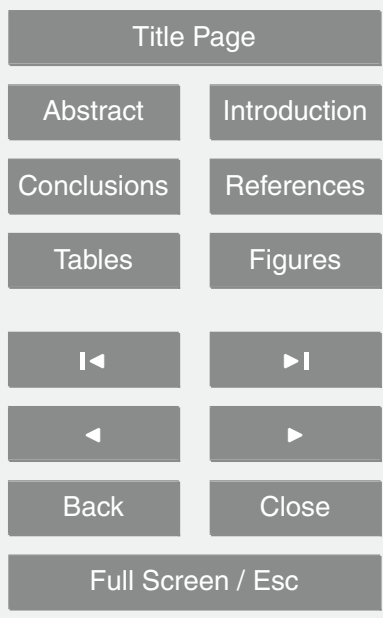

Printer-friendly Version

Interactive Discussion 


\section{ESURFD}

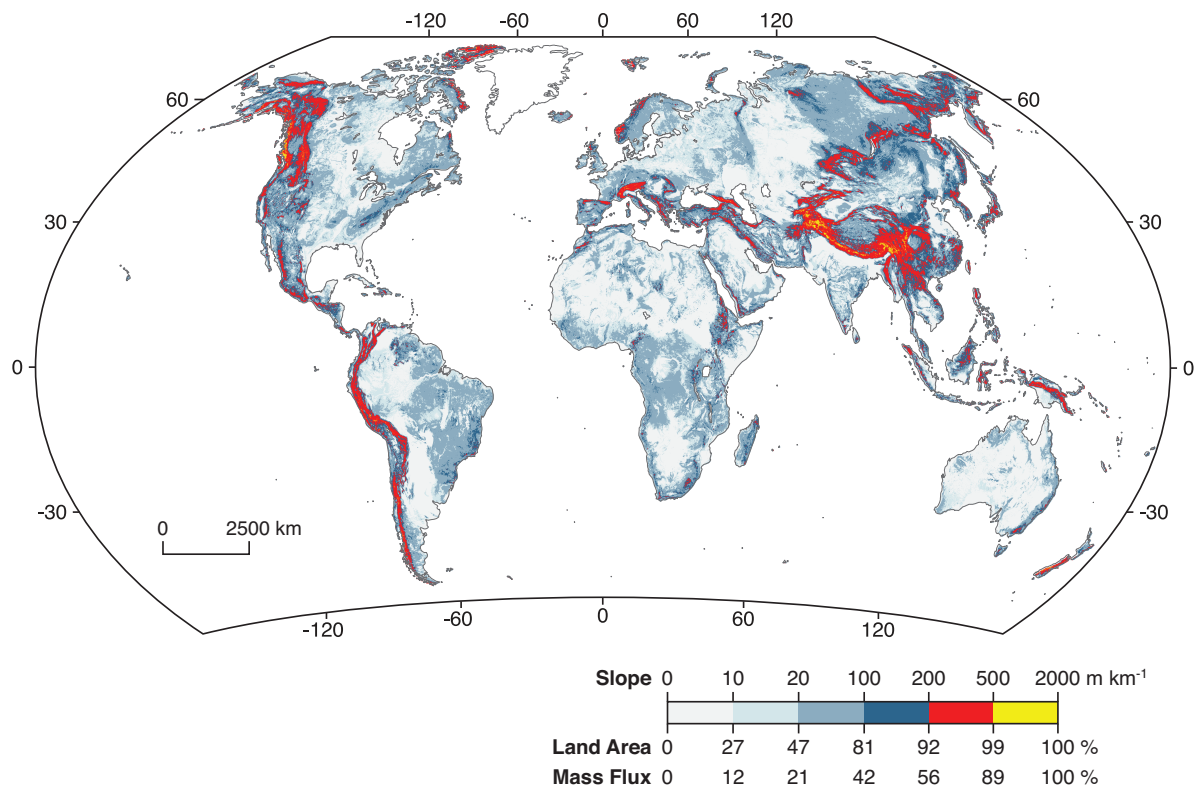

Fig. 1. Map of the world's slopes from GMTED ( $250 \mathrm{~m}$ grid), smoothed using windows with a distribution of sizes that mirrors the distribution of catchment areas in the cosmogenic nuclidederived denudation rate compilation of Willenbring et al. (2013). The scale bar in the legend reports the cumulative distributions of land area and denudational mass flux in our reanalysis of Willenbring et al.'s data using the "multiscale" smoothing routine (see text).
$2,1-17,2014$

\section{Earth is (mostly) flat, but mountains dominate global denudation}

\section{J. K. Willenbring et al.}

\section{Title Page}

Abstract

Conclusions

Tables

14

Back
Introduction

References

Figures

$>1$

Close

\section{Full Screen / Esc}

Printer-friendly Version 


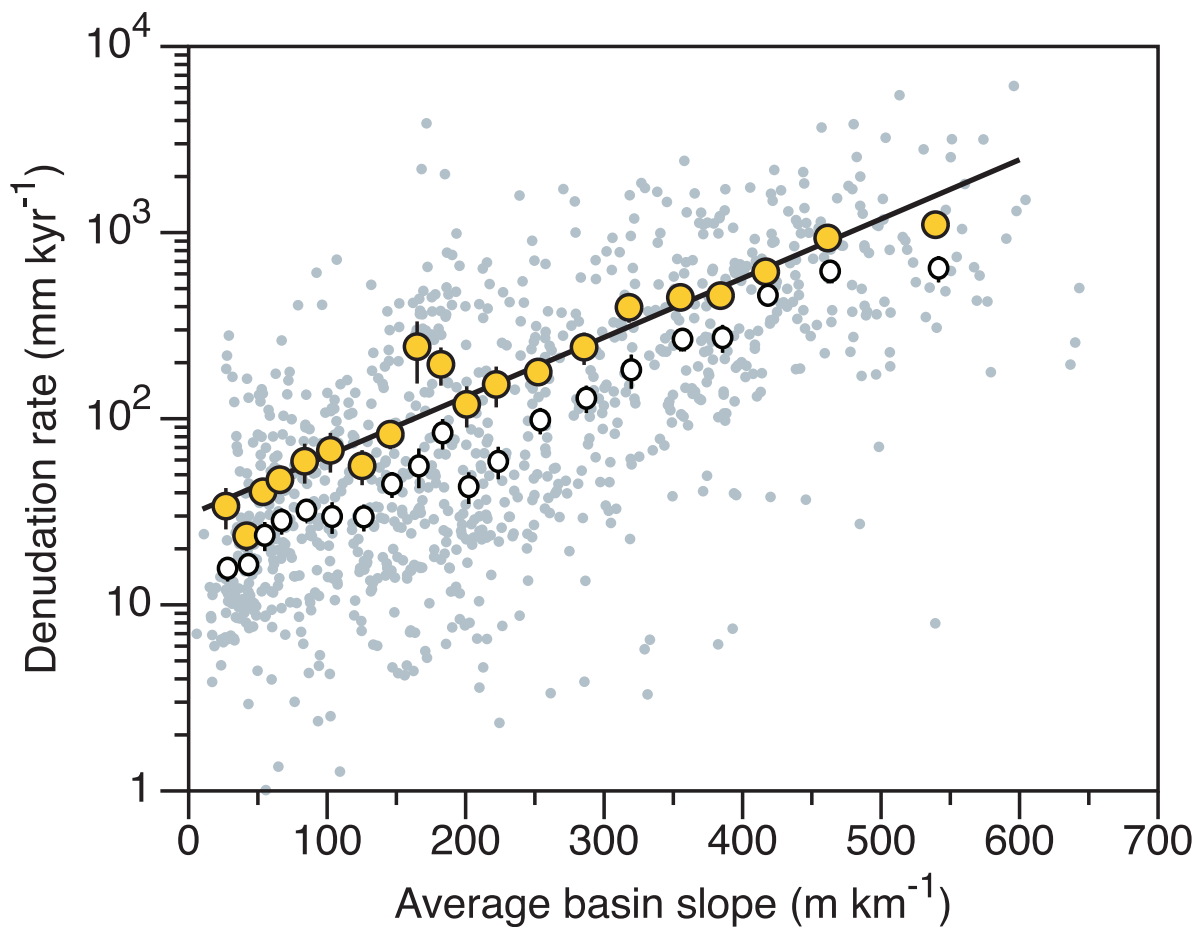

Fig. 2. Relationship between average basin slope and denudation rate for individual sample points (gray dots), 20 binned averages (yellow circles) and 20 binned averages of the log of the denudation rate (open circles). Basin slopes are estimated from the $250 \mathrm{~m}$ GMTED2010 topographic database, and thus are somewhat shallower than those reported in Willenbring et al. (2013), who used the $90 \mathrm{~m}$ SRTM data set. The binned averages represent equal numbers of sample points, rank-ordered by basin slope (shallowest $5 \%$, next $5 \%$, and so forth). The open circles exhibit log transformation bias (the mean of the logarithm of the erosion rate underestimates the logarithm of the mean erosion rate), which the binned averages (yellow circles) effectively eliminate. The yellow circles show a clear exponential relationship with basin slope.

\section{ESURFD}

2, 1-17, 2014

\section{Earth is (mostly) flat, but mountains dominate global denudation}

\section{J. K. Willenbring et al.}

\section{Title Page}

\section{Abstract}

Conclusions

Tables

14

Back

\section{Introduction}

References

Figures

$\rightarrow 1$

Close

\section{Full Screen / Esc}

Printer-friendly Version

Interactive Discussion 


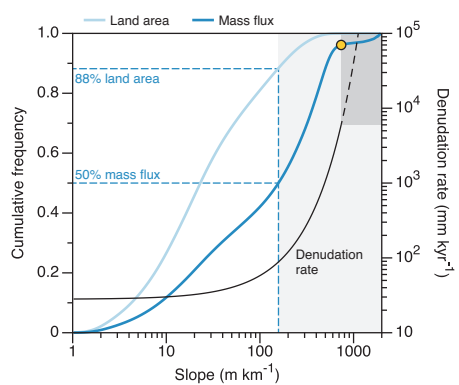

B. SRTM/GTOPO (original analysis)

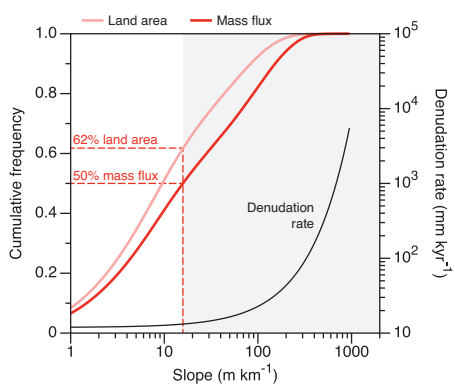

Fig. 3. Cumulative frequency distributions of land area and denudational mass flux as a function of topographic slope. (A) Results from our reanalysis, using topographic slopes measured at $250 \mathrm{~m}$ scale in both the calibration dataset and the global slope analysis, along with a "multiscale" spatial averaging technique (see text). (B) A comparable diagram for the original Willenbring et al. (2013) analysis, which used slopes measured from $90 \mathrm{~m}$ SRTM data for the calibration dataset but $1 \mathrm{~km}$ GTOPO30 topographic data for the global slope analysis, with a fixed spatial averaging scale of $25 \mathrm{~km}^{2}$. The small shaded gray area in (A) shows where the mass flux curve must be extrapolated beyond the range of the cosmogenic nuclide measurements reported in Willenbring et al. (2013). Similarly, the yellow circle in (A) shows the proportion of the total sediment flux that is contributed by areas eroding at a predicted rate that exceeds the maximum of the cosmogenic nuclide compilation.

\section{ESURFD}

$2,1-17,2014$

\section{Earth is (mostly) flat, but mountains dominate global denudation}

\section{J. K. Willenbring et al.}

\section{Title Page}

\section{Abstract}

Conclusions

Tables

14

Back

\section{Introduction}

References

Figures

$\rightarrow 1$

Close

\section{Full Screen / Esc}

Printer-friendly Version 


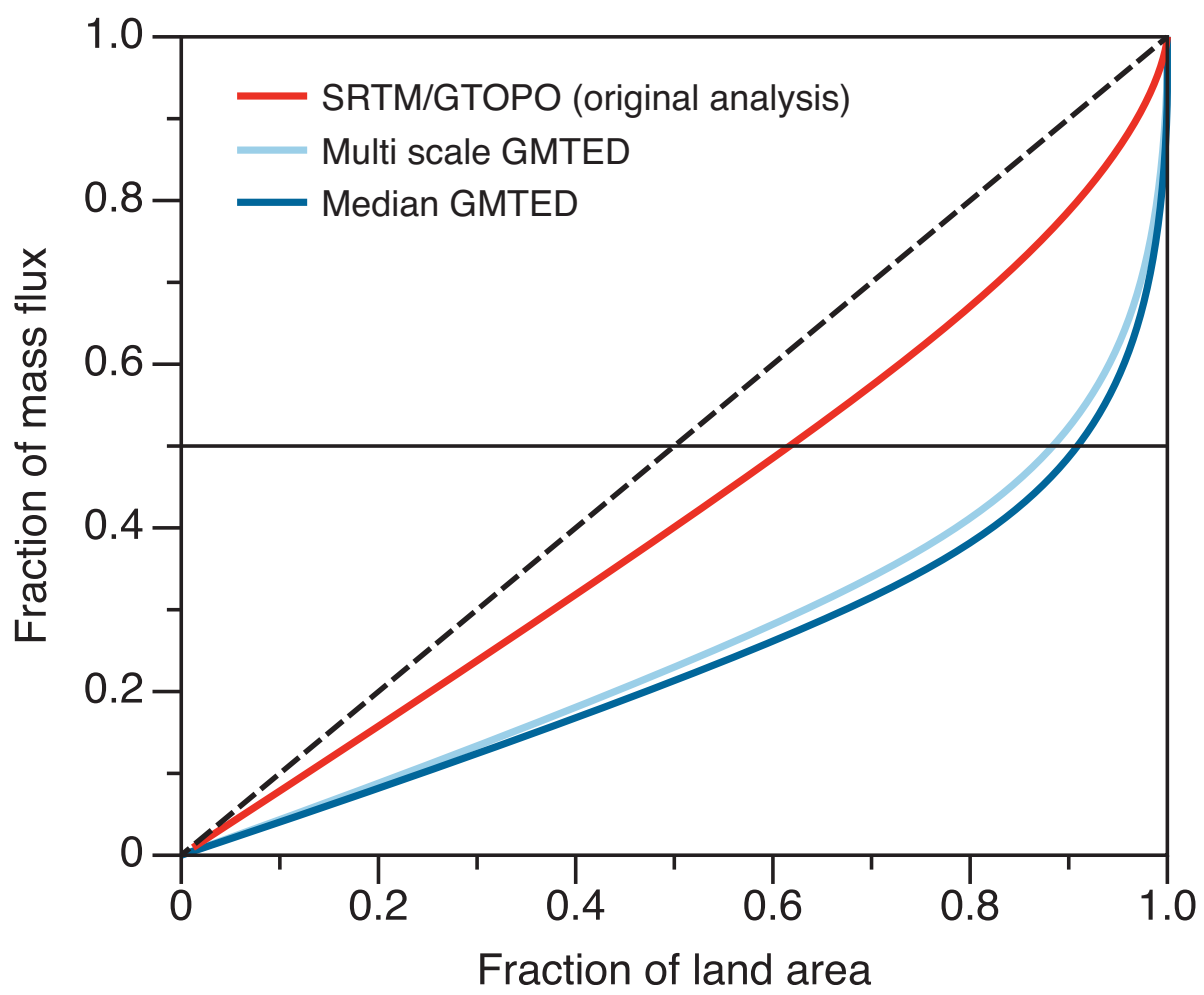

Fig. 4. Fraction of land area responsible for the Earth's continental mass flux. The previous analysis (Willenbring et al., 2013) is shown in red, and our reanalyses are shown in blue. The terms "median" and "multi-scale" refer to the different methods for spatial averaging of the global slope data, to mirror the averaging that is inherent in the catchment-based calibration data set (see text).

\section{ESURFD}

$2,1-17,2014$

\section{Earth is (mostly) flat, but mountains dominate global denudation}

\section{J. K. Willenbring et al.}

\section{Title Page}

\section{Abstract}

Conclusions

Tables

14

Back

\section{Introduction}

References

Figures

$>1$

\section{Close}

\section{Full Screen / Esc}

Printer-friendly Version

Interactive Discussion 